\title{
Functional connectome mediates the association between sleep disturbance and mental health in preadolescence
}

Fan Nils Yang ${ }^{1}$; Tina Tong Liu²; Ze Wang ${ }^{1 *}$

${ }^{1}$ Department of Diagnostic Radiology and Nuclear Medicine, University of Maryland School of Medicine, Baltimore, MD, USA.

${ }^{2}$ Section on Neurocircuitry, Laboratory of Brain and Cognition, National Institute of Mental Health, National Institutes of Health, Bethesda, MD, USA.

Correspondence

"Ze Wang, Department of Diagnostic Radiology and Nuclear Medicine, University of Maryland School of Medicine, Baltimore, MD 21201, USA.

\section{Email: Ze.Wang@som.umaryland.edu}


medRxiv preprint doi: https://doi.org/10.1101/2021.08.12.21261990; this version posted August 13, 2021. The copyright holder for this preprint (which was not certified by peer review) is the author/funder, who has granted medRxiv a license to display the preprint in perpetuity.

\section{Abstract}

\section{Background}

Sleep disturbance is known to be associated with various mental disorders and typically precedes the onset of mental disorders in youth. Given the increasingly acknowledged bidirectional influence between sleep disturbance and mental disorders, we addressed the possibility of a shared neural mechanism that underlies sleep disturbance and mental disorders in preadolescents.

\section{Methods}

We analyzed a dataset of 9350 9-10 year-old children, among whom 8845 had one-year followup data, from the Adolescent Brain and Cognitive Development (ABCD) Study. Linear mixedeffects models, mediation analysis, and longitudinal mediation analysis were used.

\section{Results}

Out of 338 unique connectivities, the effect of total sleep disturbance (TSP, from Sleep Disturbance Scale) and total problems (TP, from Child Behavior Checklist) converged in the default mode network (DMN) and its anti-correlated dorsal attention network (DAN). Within- and between-network connectivities (DMN-DAN, DMN-DMN, DAN-DAN) mediated the relationship between baseline TSD and TP at one-year follow-up and the relationship between baseline TP and TSD at one-year follow-up. Moreover, the identified network connectivities (DMN-DAN, DAN-DAN) also correlated with the total cognitive composite score from the NIH toolbox.

\section{Conclusions}

The pathway model in which sleep disturbance and mental problems affect each other through two anticorrelated brain networks (DMN and DAN) suggests a common neural mechanism between sleep disturbance and mental disorders. A less segregated DMN and DAN is also associated with negative outcomes on mental well-being, sleep disturbance, and cognition. These findings have important implications for the design of prevention and neurofeedback intervention for mental disorders and sleep problems.

Key words: functional neuroimaging; sleep; adolescent psychiatry; cognition

Highlights:

1. The impact of sleep disturbance and mental disorders on functional connectivity converged in default mode and dorsal attention networks.

2. The relationship between sleep disturbance and mental disorders was mediated via a shared brain network mechanism

3. Sleep disturbance and mental disorders at baseline can each predict the other one year later through the identified network connectivities

4. A less segregated default mode and dorsal attention networks was correlated with poorer cognitive performance. 
medRxiv preprint doi: https://doi.org/10.1101/2021.08.12.21261990; this version posted August 13, 2021. The copyright holder for this preprint (which was not certified by peer review) is the author/funder, who has granted medRxiv a license to display the preprint in perpetuity. It is made available under a CC-BY-NC-ND 4.0 International license .

\section{Introduction}

Mental disorders tend to share similar risk factors or biomarkers, and respond to the same therapies (Caspi and Moffitt, 2018). Both theoretical and empirical evidence suggests that this comorbidity might be due to the nonspecificity of the functional neurocircuit (Lees et al., 2021; McTeague et al., 2017; Menon, 2011; Sha et al., 2019). Specifically, according to the triple network model, a wide variety of psychopathologies are associated with aberrant functional connectivity within and between three large-scale neurocognitive networks, i.e. salience network, frontoparietal network, and default mode network, as well as subnetworks such as ventral and dorsal attention networks (Menon, 2011). This triple network model is further corroborated by recent results (Lees et al., 2021; McTeague et al., 2017; Sha et al., 2019), including one study that demonstrated that common functional network disruptions in default mode, ventral and dorsal attention networks were linked to all dimensions of psychopathology in preadolescents (Lees et al., 2021).

Moreover, individuals with mental disorders often experience varying degrees of sleep disturbance (Baglioni et al., 2016; Tesler et al., 2013). Recent studies showed that sleep disturbance and mental disorders could aggravate each other in a reciprocal manner (Alfano et al., 2007; Cox and Olatunji, 2016; Gregory and Sadeh, 2016; Hansen et al., 2014; Tesler et al., 2013). On the one hand, longitudinal studies have shown that sleep disturbance in youth likely precedes and exacerbates symptoms of attention deficit hyperactivity disorder (ADHD) (Scott et al., 2013) and mood and anxiety disorders (Goldstone et al., 2020; Gregory et al., 2009, 2005; Jansen et al., 2011). On the other hand, greater polygenic risk factors for various mental disorders, i.e. ADHD, mood and anxiety disorders, may contribute to greater sleep disturbance among children (Ohi et al., 2021). These findings strongly suggest a potentially shared neural mechanism between sleep disturbance and mental disorders, which has not been demonstrated to date.

The purpose of this study was to address this open question using resting-state functional connectivity (rs-FC). rs-FC is an emerging fMRI technique for studying brain networks and cognition as well as their alterations related to brain disease (Gabrieli et al., 2015; Woo et al., 2017). rs-FC measure is highly reproducible within an individual across scan sessions (Finn et al., 2015; Noble et al., 2019). Thus, it has been recognized as a promising neural biomarker for assessing neurocognitive development and identifying aspects of intrinsic brain network organization that are related to cognition and disease status. Similar to the role of the triple network model in mental disorders, altered functional connectivity within and between the default mode network and its anticorrelated networks, including dorsal and ventral attention networks, were found in sleep-deprived adults (Chee and Zhou, 2019; De Havas et al., 2012; Kaufmann et al., 2016; Sämann et al., 2010).

However, few studies have investigated the associations between functional connectivity and sleep disturbance in preadolescence, which is a critical period for brain development. 
medRxiv preprint doi: https://doi.org/10.1101/2021.08.12.21261990; this version posted August 13, 2021. The copyright holder for this preprint (which was not certified by peer review) is the author/funder, who has granted medRxiv a license to display the preprint in perpetuity.

It is made available under a CC-BY-NC-ND 4.0 International license .

Coincidentally, the onset of mental disorders often starts around the same time, i.e. childhood or adolescence (Kessler et al., 2007; Tesler et al., 2013). To fill the gap of associations between sleep disturbance, mental disorders, and functional connectivity in preadolescence, we analyzed the large data from the Adolescent Brain Cognitive Development (ABCD, https://abcdstudy.org) study, the largest observational and normative project (over 11,000 children) on brain development and child health to date.

We hypothesized that sleep disturbance and mental disorders have similar effects on rs-FC. Out of 338 unique connectivity measures tested, the effect of sleep disturbance and mental disorders converged in the between- and within- network connectivities in the default mode network and one of its anti-correlated networks (i.e. dorsal attention network). In addition to identifying network connectivities that mediated the association between sleep disturbance and mental disorders, we revealed the associations between network connectivities and cognition. Longitudinal analyses demonstrated that these three network connectivities mediated the effect of sleep disturbance on mental disorders one year later and the effect of mental disorders on sleep disturbance one year later.

\section{Methods}

Participants

The ABCD study includes baseline data from more than 11,000 9-10 year olds (Casey et al., 2018). Data were collected from 21 sites across the United State, approved by institutional review boards (IRB) at the University of California, San Diego as well as at each local site. Parents' written informed consent and children's assent were obtained at each site. Recruitment followed demographic distribution (sex, race, ethnicity, household income, etc.) of the general population in the United States. Details about the protocols are available at the ABCD study website (https://abcdstudy.org/scientists/protocols/).

In total, data from 11,878 children are provided at baseline. Among them, 9387 passed the rsfmri QC (imgincl_rsfmri_include) provided by ABCD study (Hagler et al., 2019). An additional 37 children were excluded due to missing values on network connectivity $(n=14)$, total problems $(n=21)$, or total sleep disturbance $(n=2)$. Thus, the total number of children included in the current study was 9350 . Table 1 provides the detailed demographic information.

Sleep measures

Total sleep disturbance (TSD) and its one year follow-up was calculated from the ABCD Parentreported Sleep Disturbance Scale for Children (abcd_sdss01) as the sum of six scores corresponding to six different sleep disorders, including Disorders of Initiating and Maintaining 
medRxiv preprint doi: https://doi.org/10.1101/2021.08.12.21261990; this version posted August 13, 2021. The copyright holder for this preprint (which was not certified by peer review) is the author/funder, who has granted medRxiv a license to display the preprint in perpetuity.

It is made available under a CC-BY-NC-ND 4.0 International license .

Sleep, Sleep Breathing disorders, Disorder of Arousal, Sleep-Wake transition Disorders, Disorders of Excessive Somnolence, and Sleep Hyperhidrosis (Bruni et al., 1996).

Mental health measures

Children's dimensional psychopathology and adaptive functioning were assessed by the Parentreported Child Behavior Checklist Scores (abcd_cbcls01). The total score of psychiatric problems (total problems t score) and its one year follow-up was calculated based on scores of ten empirically-based syndromes, i.e. anxious/depressed, withdrawn/depressed, somatic complaints, social problems, thought problems, attention problems, rule-breaking behavior, aggressive behavior, internalizing broad band score and externalizing broad band score (Achenbach and Rescorla, 2004).

Cognitive measures

Total Cognitive Composite Fully-Corrected T-score (abcd_tbss01, baseline only, not data available at one year follow-up) of the NIH Cognition Battery Toolbox was used as the measure for general cognitive function measure (Akshoomoff et al., 2013). It is the sum of the scores from seven cognitive components: language vocabulary knowledge, attention, cognitive control, working memory, executive function, episodic memory, and language.

Network connectivity

Preprocessing of the functional connectivity analysis and the network connectivity strengths were provided by the ABCD consortium. Detailed MRI scan parameters and preprocessing steps have been reported and discussed (Hagler et al., 2019). Briefly, preprocessing of rs-FC included registration, distortion correction, normalization, regression of 24 motion parameters, outliers with framewise displacement higher than $3 \mathrm{~mm}$, and signals from whither matter, cerebral spinal fluid, and whole-brain. Within- or between-network connectivity were calculated as the average fisher-transferred functional connectivity between each pair of ROls within or between networks (13 networks in total) based on the Gordon altas (Gordon et al., 2016). In addition, network connectivity between each network and each subcortical region (19 subcortical regions in total) were also calculated (Fischl et al., 2002). Quality controls were performed by trained ABCD staff (Hagler et al., 2019) and were used as an inclusion criterion. Sites effects were harmonized by the ComBat method (Johnson et al., 2007; Yang et al., 2021; Yu et al., 2018). Network connectivity measures were not available at one year follow-up.

\section{Statistical analyses}

Linear Mixed-effects Models (LME, implemented through function fitlme in Matlab ) were used to investigate the effect of total problems or total sleep disturbance on network connectivity. All models included fixed-effect covariates for age, sex at birth, race (black, white, and others), pubertal status (1-4, assessed by ABCD Youth Pubertal Development Scale and Menstrual Cycle Survey History), and random effects for family relatives nested within sites.

The mediation toolbox (https://github.com/canlab/MediationToolbox) was used to perform all the mediation analyses (Wager et al., 2009, 2008). Here, the independent variable is total sleep disturbance/total problems, the dependent variable is total problems/total sleep disturbance, and 
medRxiv preprint doi: https://doi.org/10.1101/2021.08.12.21261990; this version posted August 13, 2021. The copyright holder for this preprint (which was not certified by peer review) is the author/funder, who has granted medRxiv a license to display the preprint in perpetuity.

It is made available under a CC-BY-NC-ND 4.0 International license .

the mediator is the network connectivity identified through LME. All above-mentioned covariates (age, sex, race, pubertal status, family relatives, and sites) were controlled in the mediation analyses. The significance of the mediation analyses was estimated using bootstrap sampling with 10,000 random-generated samples.

Longitudinal analyses

8845 of the 9350 children participated in the one-year follow-up study (see Table 1). Mediation analyses were performed to test the longitudinal associations between total sleep disturbance, total problems, and network connectivities. Specifically, we tested whether network connectivities mediated the associations between total sleep disturbance at baseline and total problems one year later (controlled for baseline total problems), and between total problems at baseline and total sleep disturbance one year later (controlled for baseline total sleep disturbance). Additional covariates including baseline age, sex, race, baseline pubertal statuse, familiy relatives, and sites.

\section{Results}

Total sleep disturbance and network connectivity

The distribution of TSD was skewed, so we log-transformed the data to approximate normality. In total, 91 within- and between-network connectivities and 247 network-subcortical connectivities were tested (Fig. 1). Out of the 338 unique comparisons, TSD had a significant impact on only three network connectivities (FDR corrected for multiple comparisons, see asterisks in Fig. 1), DMN-DAN $\left(\beta=0.0329, R^{2}=0.0638, p<1 \mathrm{e}-4\right)$, DMN-DMN $\left(\beta=-0.0326, R^{2}\right.$ $=0.0489, p=0.0003$, and DAN-DAN $\left(\beta=-0.0355, R^{2}=0.0241, p=0.0003\right)$.

\section{Total problems and network connectivity}

Similarly, the effect of total problems on 338 unique network connectivities were tested. Thirteen associations between total problems and network connectivity survived FDR correction (see Fig. 2). Interestingly, the same three network connectivities impacted by total sleep disturbance were also influenced by total problems, i.e. DMN-DAN $\left(\beta=0.00033, R^{2}=0.0655, p<1 \mathrm{e}-7\right)$, DMN$\operatorname{DMN}\left(\beta=-0.00026, R^{2}=0.0497, p=1.4 \mathrm{e}-4\right)$, and DAN-DAN $\left(\beta=-0.00032, R^{2}=0.0245, p=\right.$ 1.6e-5).

Mediation analysis

Given that the impact of TSD and TP converged on the same three network connectivities (DMN-DAN, DMN-DMN, DAN-DAN), we further conducted a mediation analysis to explore the underlying mechanism by which TSD influences TP, or TP influences TSD, through a common mediator variable (DMN-DAN, DMN-DMN, or DAN-DAN connectivity). In other words, we tested whether these three network connectivities mediated the relationship between total sleep disturbance and total problems. We found that all three network connectivity measures significantly mediated the effect of sleep disturbance on total problems (all $p<0.005 ; 95 \% \mathrm{Cl}$ did not include 0 , see Fig. 3 A-C). However, only the within-network connectivity (DMN-DMN) significantly mediated the effect of total problems on sleep disturbance $(p=0.016 ; \beta=0.0007$; $95 \% \mathrm{Cl}, 0.0001-0.0014$, see Fig. $3 \mathrm{D})$. 
Correlation analysis

Follow-up partial correlation analysis showed that DMN-DAN and DAN-DAN were significantly correlated with the Total Cognitive Composite Fully-Corrected T-score $(r=-0.0361$ and 0.0231 , $p=0.0008$ and 0.032 , FDR corrected $p=0.0025$ and 0.0483 , respectively), suggesting that these two network connectivities might be important for general cognitive functions in preadolescence.

Longitudinal mediation analysis

Longitudinal mediation analysis revealed that all three network connectivities mediated the effect of total sleep disturbance at baseline on total problems one year later, even after controlling for baseline total problems (all $p<0.005 ; 95 \% \mathrm{Cl}$ did not include 0 , see Fig. $4 \mathrm{~A}-\mathrm{C}$ ). Interestingly, distinct from the pattern that only DMN-DMN mediated the effect of total problems on total sleep disturbance at baseline, all three network connectivities mediated the effect of total problems at baseline on total sleep disturbance one year later, after adjusting for baseline total sleep disturbance (all $p<0.005 ; 95 \% \mathrm{Cl}$ did not include 0, see Fig. $4 \mathrm{D}-\mathrm{E}$ ). 
Table 1. Demographic information of the participants from the ABCD dataset included in the present study.

\begin{tabular}{lcc}
\hline Characteristic & Baseline & 1 year Follow-up \\
& N or Mean (SD) & N or Mean (SD) \\
\hline Age (month) & $119.3(7.5)$ & $131.4(7.8)$ \\
Sex at birth & & \\
female & 4674 & 4412 \\
male & 4676 & 4433 \\
Race & & \\
White & 6101 & 5872 \\
Black & 1340 & 1198 \\
Other (mixes or Asians) & 1909 & 1775 \\
Pubertal Status & $1.8(0.9)^{1}$ & $2.1(1.0)^{3}$ \\
Total Problems & $45.4(11.2)$ & $45.0(11.0)^{4}$ \\
Total Sleep Disturbance & $36.3(8.0)$ & $36.5(7.9)^{5}$ \\
Total Cognitive Composite Score & $48.3(11.1)^{2}$ & $\mathrm{~N} / \mathrm{A}^{6}$ \\
Number of children & 9350 & 8845 \\
\hline
\end{tabular}

Note:

1. 305 children have missing values;

2. 752 children have missing values;

3. 3090 children have missing values;

4. 33 children have missing values;

5. 28 children have missing values;

6. Total cognitive composite score did not have 1 year follow-up data. 


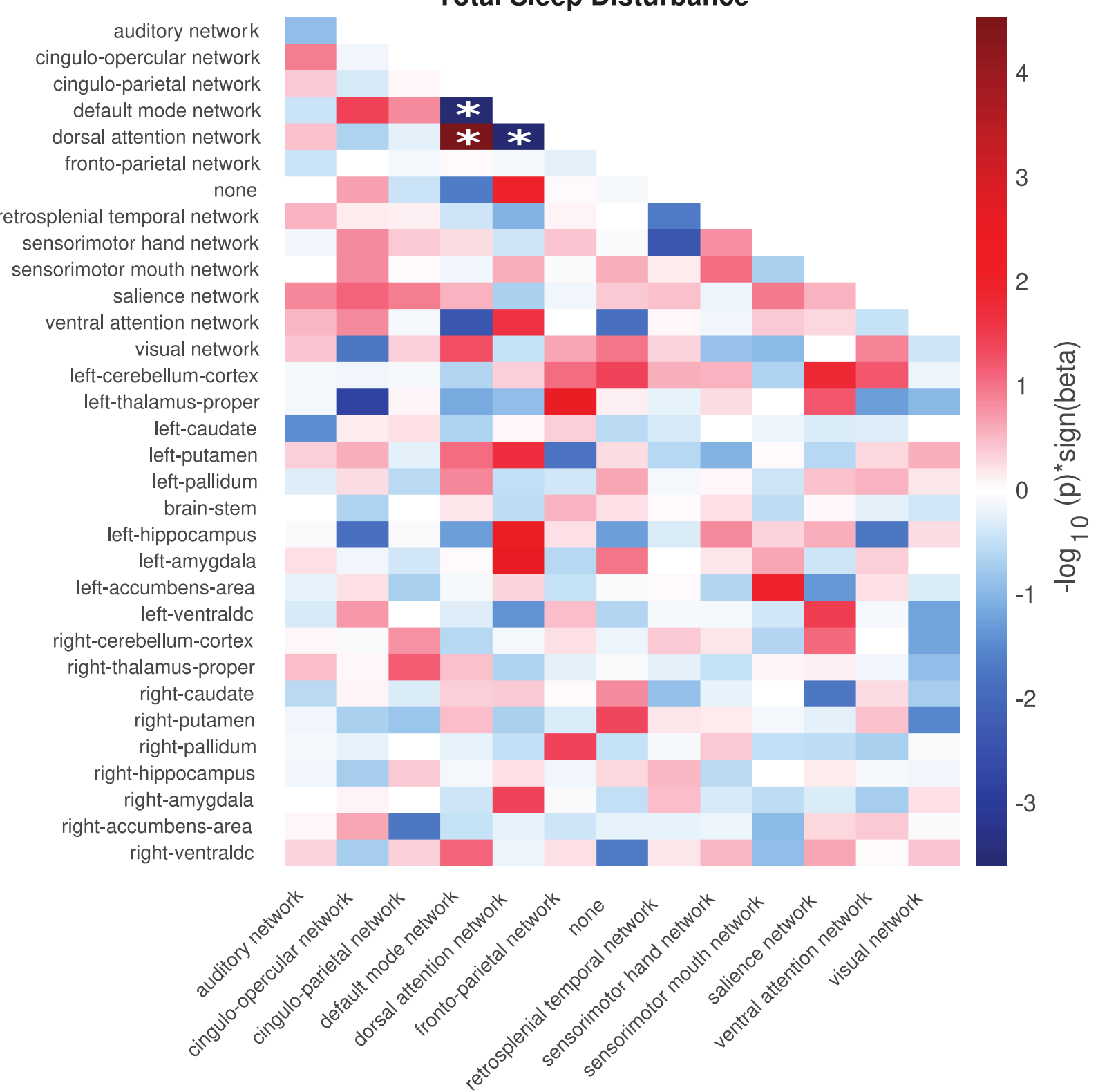

Figure 1. The effect of total sleep disturbance on network connectivity measures. Color represents negative log-transformed $p$ value times the sign of beta value of total sleep disturbance. That is, red/blue means positive/negative association between total sleep disturbance and network connectivity measures, respectively. Only unique network connectivity measures were shown in the matrix (i.e. top right was intentionally left blank). * denotes network connectivity that survived FDR correction for multiple comparisons out of 338 unique comparisons (91 within- and between-network connectivities and 247 network-subcortical connectivities). 


\section{Total Problems}

auditory network cingulo-opercular network cingulo-parietal network default mode network dorsal attention network fronto-parietal network none retrosplenial temporal network sensorimotor hand network sensorimotor mouth network salience network ventral attention network visual network

left-cerebellum-cortex left-thalamus-proper left-caudate left-putamen left-pallidum brain-stem left-hippocampus left-amygdala left-accumbens-area left-ventraldc right-cerebellum-cortex right-thalamus-proper right-caudate right-putamen right-pallidum right-hippocampus right-amygdala right-accumbens-area right-ventraldc
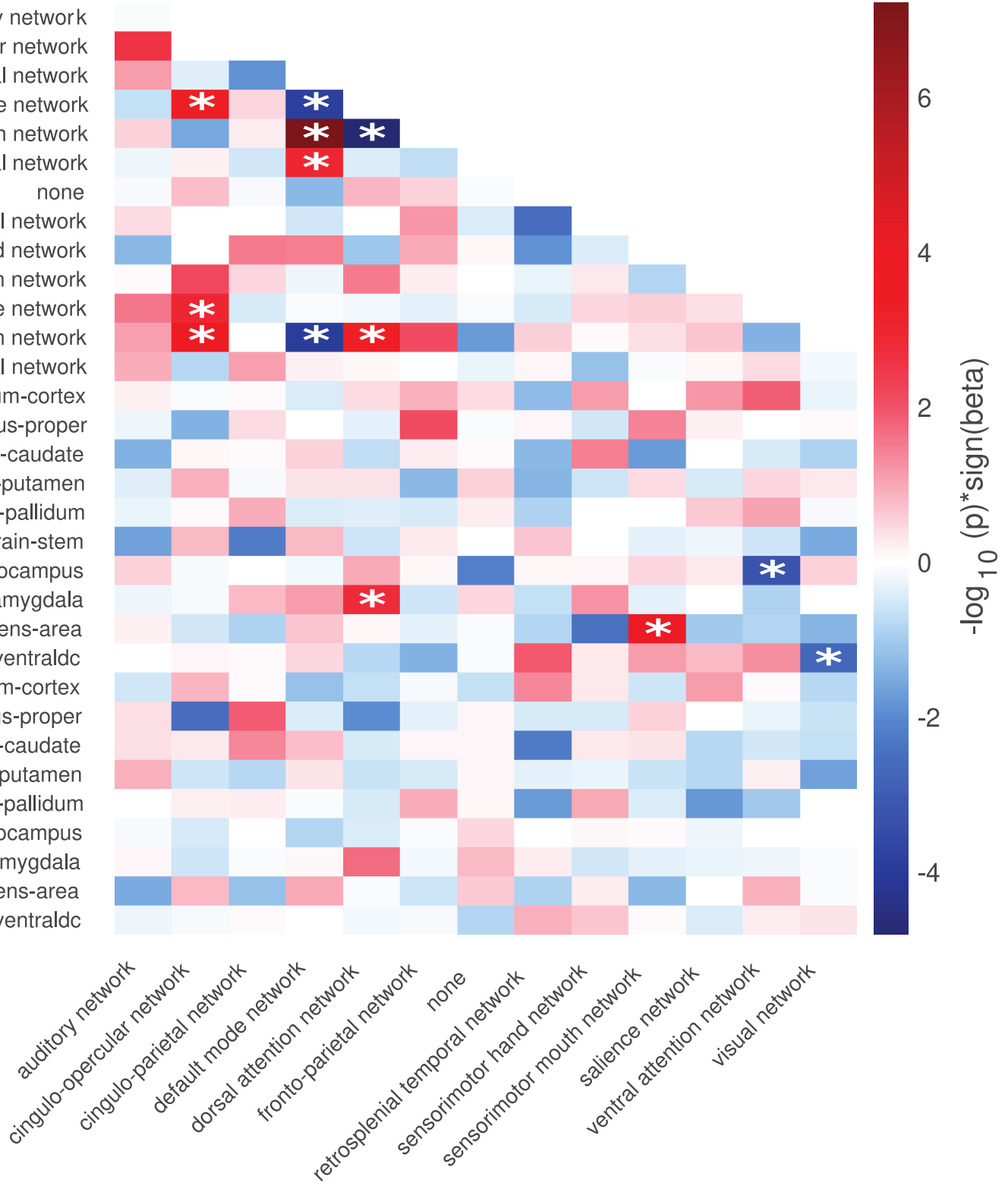

Figure 2. The effect of total problems on network connectivity measures. Color represents negative log-transformed $p$ value times the sign of beta value of total problems. That is, red/blue means positive/negative association between total problems and network connectivity measures, respectively. Only unique network connectivity measures were shown in the matrix (i.e. top right was intentionally left blank). ${ }^{*}$ denote network connectivity that survived FDR correction for multiple comparisons out of 338 unique comparisons (91 within- and betweennetwork connectivities and 247 network-subcortical connectivities).. 

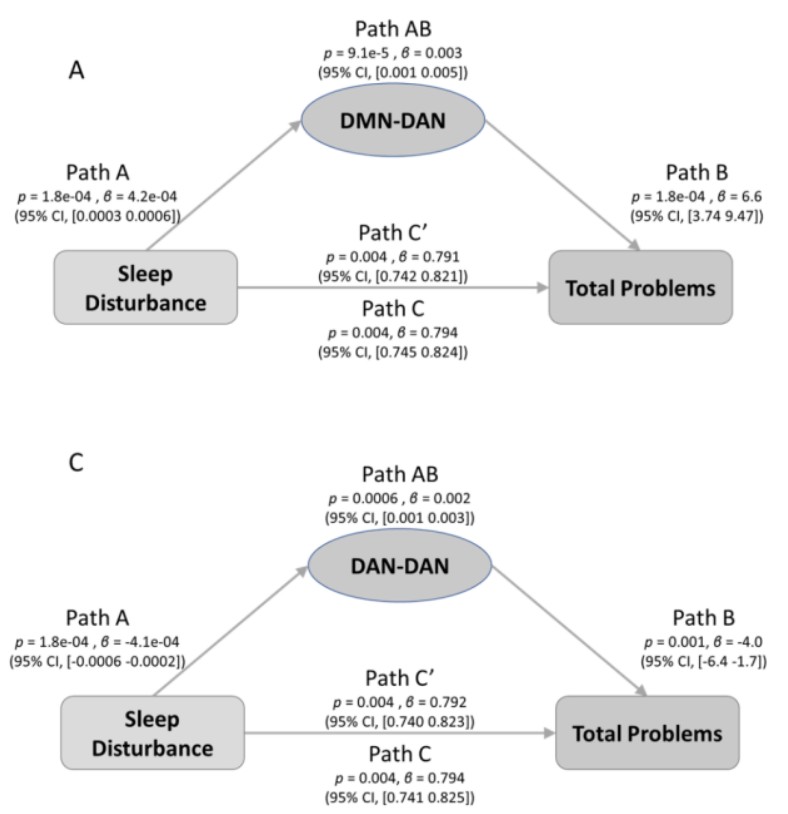
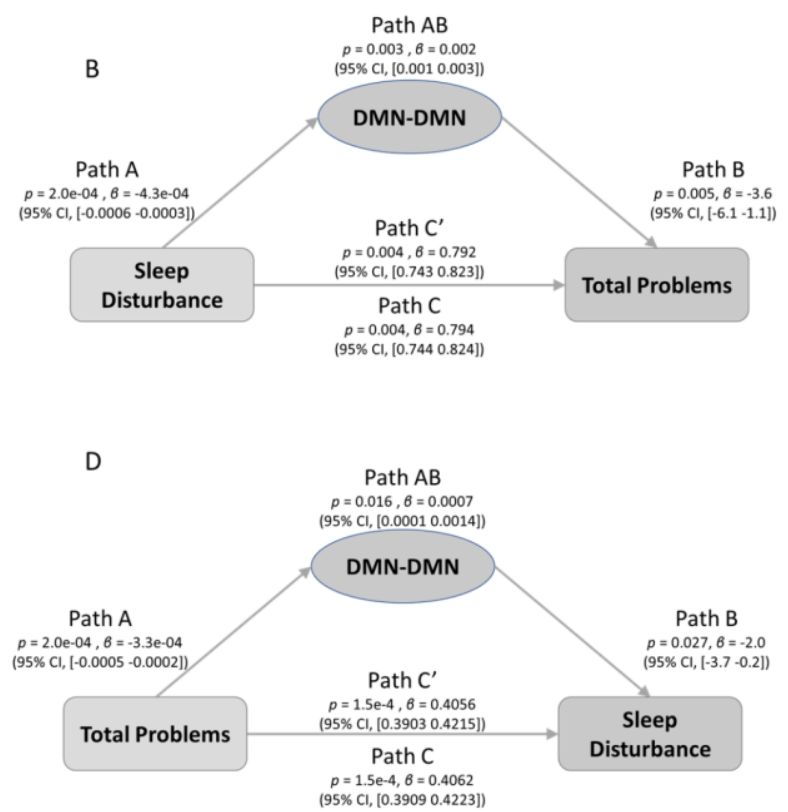

Figure 3. Network connectivities mediated the relationship between total sleep disturbance and total problems $(A-C)$ and the relationship between total problems and total sleep disturbance (D). A, DMN-DAN mediated the effect of total sleep disturbance on total problems (Path AB: $p=9.1 \mathrm{e}-5 ; \beta=0.003 ; 95 \% \mathrm{Cl}, 0.001-0.005) . B$, DMN-DMN mediated the effect of total sleep disturbance on total problems (Path $A B: p=0.003 ; \beta=0.002 ; 95 \% \mathrm{Cl}, 0.001-0.003$ ). $C$, DANDAN mediated the effect of total sleep disturbance on total problems (Path AB: $p=0.0006 ; \beta=$ $0.002 ; 95 \% \mathrm{Cl}, 0.001-0.003)$. $\boldsymbol{D}$, DMN-DMN mediated the effect of total problems on total sleep disturbance (Path $\mathrm{AB}$ : $p=0.016 ; \beta=0.0007 ; 95 \% \mathrm{Cl}, 0.0001-0.0014$ ). DMN, default mode network; DAN, dorsal attention network. 

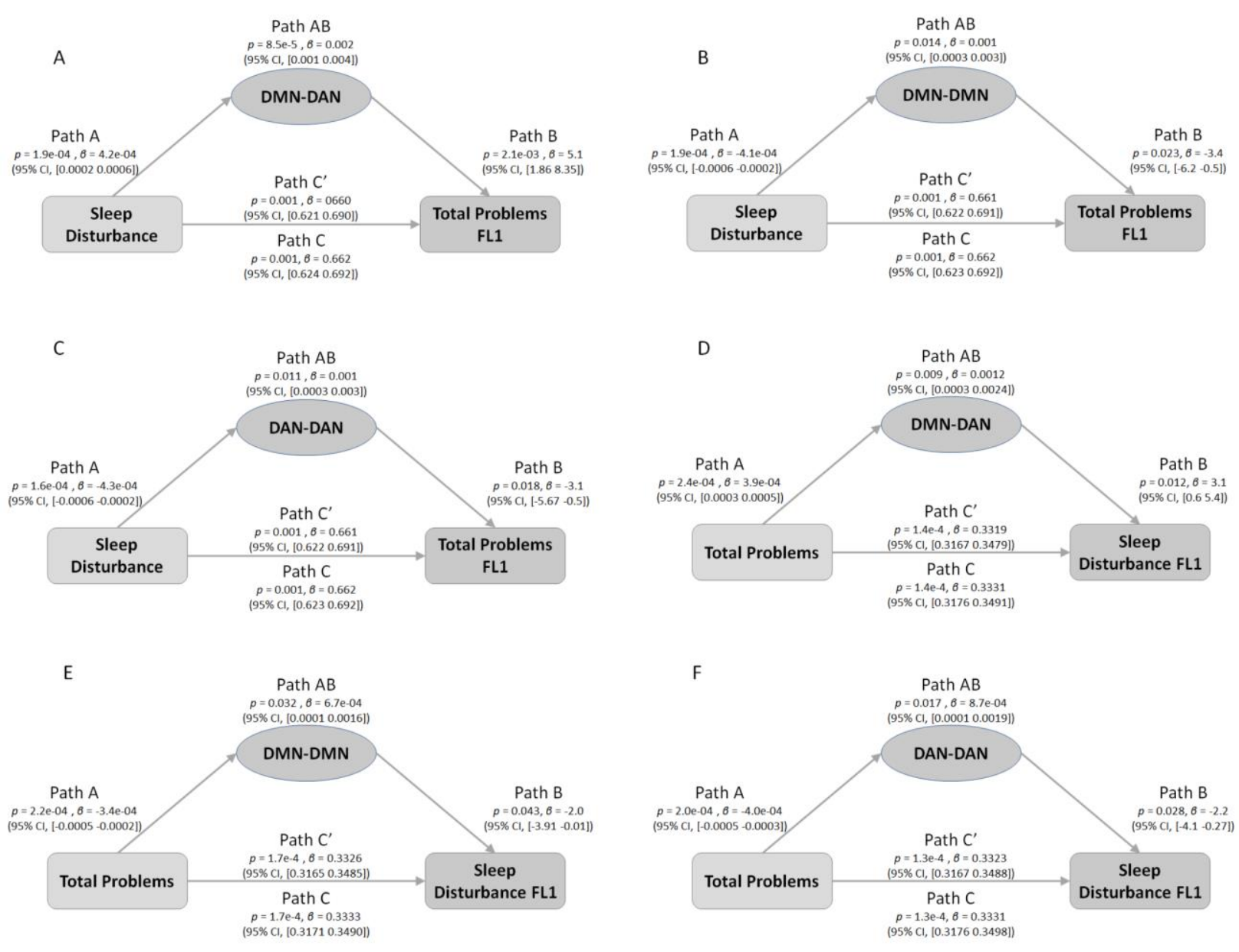

Figure 4. Network connectivities mediated both the relationship between total sleep disturbance (at baseline) and total problems (at one year follow-up, FL1) (A-C) and the relationship between total problems (at baseline) and total sleep disturbance (at FL1) (D-F). A, DMN-DAN mediated the effect of total sleep disturbance at baseline on total problems at FL1 (Path AB: $p=8.5 \mathrm{e}-5 ; \beta=$ $0.002 ; 95 \% \mathrm{Cl}, 0.001-0.004)$. B, DMN-DMN mediated the effect of total sleep disturbance at baseline on total problems at FL1 (Path AB: $p=0.014 ; \beta=0.001 ; 95 \% \mathrm{Cl}, 0.001-0.003$ ). $C$, DANDAN mediated the effect of total sleep disturbance at baseline on total problems at FL1 (Path AB: $p=0.011 ; \beta=0.001 ; 95 \% \mathrm{Cl}, 0.001-0.003)$. $\boldsymbol{D}$, DMN-DAN mediated the effect of total problems at baseline on total sleep disturbance at FL1 (Path AB: $p=0.009 ; \beta=0.0012 ; 95 \% \mathrm{Cl}$, 0.0003-0.0024). E, DMN-DMN mediated the effect of total problems at baseline on total sleep disturbance FL1 (Path AB: $p=0.032 ; \beta=6.7 \mathrm{e}-4 ; 95 \% \mathrm{Cl}, 0.0001-0.0016)$. $\boldsymbol{F}$, DAN-DAN mediated the effect of total problems at baseline on total sleep disturbance at FL1 (Path AB: $p=0.017 ; \beta=8.7 \mathrm{e}-4 ; 95 \% \mathrm{Cl}, 0.0001-0.0019)$. Each longitudinal mediation analysis controlled for the corresponding baseline data of the dependent variable, e.g., for diagram $A$, baseline total problems was added as a covariate. DMN, default mode network; DAN, dorsal attention network; FL1, one year follow-up. 
medRxiv preprint doi: https://doi.org/10.1101/2021.08.12.21261990; this version posted August 13, 2021. The copyright holder for this preprint (which was not certified by peer review) is the author/funder, who has granted medRxiv a license to display the preprint in perpetuity. It is made available under a CC-BY-NC-ND 4.0 International license .

\section{Discussion}

Based on data from a large cohort of preadolescents enrolled in the ABCD dataset study, our work identified robust relationships between network connectivity, cognition, sleep disturbance, and mental health. Total sleep disturbance and total problems both impact network connectivity and their relationship is mediated by network connectivity. The effects of sleep disturbance on total problems is mediated by three network connectivity measures, i.e. DMN-DMN, DMN-DAN, and DAN-DAN. In contrast, only DMN-DMN mediates the effect of total problems on sleep disturbance. Follow-up analyses showed that the degree to which DMN and DAN are anticorrelated (as two segregated modules) significantly correlates with the total cognition score. Longitudinal analysis revealed that total sleep disturbance and total problems at baseline can each predict the other one year later through the identified three network connectivities. These results confirm our hypothesis that sleep disturbance and mental disorders have similar impact on resting-state functional connectivity. Using a data-driven approach, we discovered that their impact converged in the between- and within- network connectivities in the DMN and one of its anti-correlated networks, DAN. Our findings suggest a common neural mechanism through which sleep disturbance and mental problems may exacerbate each other at both baseline and at one-year follow-up.

DMN is generally considered an integrated system that is associated with many different aspects of self-related mental processes such as autobiographical memory, internal thoughts, emotion regulations (Menon, 2011). Given these roles, it is not surprising that abnormal connectivity within DMN has been involved in almost every major psychiatric disorder, including dementia, schizophrenia, anxiety and depression, autism, and ADHD (Broyd et al., 2009). Consistent with these observations, we found that total problems, a summary score of various mental problems, was negatively correlated with DMN's within-network connectivity (DMNDMN) in the current study. That is, higher scores in total problems were correlated with weaker connectivities between brain regions within DMN. Moreover, we demonstrated that total problems had an indirect detrimental effect on sleep disturbance through DMN-DMN in preadolescence.

Unlike DMN, DAN is considered a "task-positive" network (Fox et al., 2005). Under externally directed cognitive tasks (e.g., visual search), DAN activation and DMN deactivation usually cooccur. This anticorrelation between DMN and DAN emerges in childhood and continues to develop during adolescence (Fair et al., 2009). In the current study, we found that both sleep disturbance and total problems were associated with the connectivity strength between DMN and DAN. Moreover, we found that a less separated DMN-DAN is also correlated with lower total cognition scores, suggesting that a segregation between DMN and DAN might be a critical factor accounting for one's cognitive performance, in line with a previous study showing that variations in network configurations, e.g. less segregation of DMN-DAN affects the development of cognition (Gu et al., 2015). 
medRxiv preprint doi: https://doi.org/10.1101/2021.08.12.21261990; this version posted August 13, 2021. The copyright holder for this preprint (which was not certified by peer review) is the author/funder, who has granted medRxiv a license to display the preprint in perpetuity. It is made available under a CC-BY-NC-ND 4.0 International license .

Emerging evidence suggests that symptom severity of various mental disorders and sleep disturbance could impact each other in a bi-directional manner (Tesler et al., 2013). For example, less sleep disturbance was found in children who received treatment for anxiety disorders compared to those who received placebo (Alfano et al., 2007). In youth with mood disorders, sleep disturbance was associated with more severe symptomatology, longer episodes, and increased risk for relapse (Emslie et al., 2012; Liu et al., 2007). To our knowledge, the current study first explains the co-occurrence and bi-directionality of mental disorders and sleep disturbance by identifying a shared network mechanism between sleep disturbance and total problems, i.e. within- and between- network connectivity in DMN and DAN. Mediation analysis and longitudinal mediation analysis further confirmed that sleep disturbance and mental disorders could affect each other via these three network connectivities (DMN-DAN, DAN-DAN, and DMN-DMN).

The specificity of the functional networks (DMN-DAN, DAN-DAN, and DMN-DMN) as the mediator identified throughout longitudinal mediation analyses can further inform the design and application of real-time $\mathrm{fMRI}$ connectivity-based neurofeedback training. Real-time fMRI neurofeedback (rt-fMRI-NF) is an emerging non-invasive technique to modulate aberrant neurocircuitry, with the potential to induce long-term symptom reductions in patients with various mental disorders (Linhartová et al., 2019). In our pathway model, the DMN-DAN connectivity mediated both the bidirectional and longitudinal relationship between mental disorders and sleep disturbance. Thus, regulating DMN-DAN connectivity strength can potentially result in reduced mental problems and sleep disturbance, potentially yielding a positive and long-term effect in individuals at-risk for mental disorders and sleep disturbance.

Several limitations in the current study should be noted. First, the effect sizes found in the current study with large sample sizes are relatively small compared to those reported in the literature based on much smaller sample sizes. Despite a small $r$ value of the correlation between DMN-DAN and total cognition (-0.036), according to ABCD analysis guidelines (Dick et al., 2021), a -0.036 r value in about 10,000 participants has statistical power higher than 0.9 , which is considered well-powered. In addition, a previous large sample-size study found even the most significant results can only explain around $1 \%$ of the total variances (Miller et al., 2016). Second, we focused on the high-level commonality between sleep disturbance and various mental disorders (rather than each type of mental disorder). Thus, we did not investigate the relationship between sleep disturbance and each specific type of mental disorder. Caveat is needed when interpreting the current findings with regard to specific mental disorders, e.g. depression, anxiety disorders, etc.

Taken together, our results shed light on a shared and stable neural mechanism between sleep disturbance and mental disorders. The network connectivity between DMN and DAN that mediated the bidirectional and long-term relationship between sleep disturbance and mental disorders are key target brain networks for neurofeedback training or behavioral therapy. Future work may examine the effectiveness of regulating connectivity strength between DMN and DAN in inducing positive behavioral change related to mental health and sleep problems. 
medRxiv preprint doi: https://doi.org/10.1101/2021.08.12.21261990; this version posted August 13, 2021. The copyright holder for this preprint (which was not certified by peer review) is the author/funder, who has granted medRxiv a license to display the preprint in perpetuity.

It is made available under a CC-BY-NC-ND 4.0 International license.

\section{Acknowledgement}

This study was supported by NIH/NIA grants R01AG060054, R01 AG070227. 
medRxiv preprint doi: https://doi.org/10.1101/2021.08.12.21261990; this version posted August 13, 2021. The copyright holder for this preprint (which was not certified by peer review) is the author/funder, who has granted medRxiv a license to display the preprint in perpetuity. It is made available under a CC-BY-NC-ND 4.0 International license .

\section{References}

Achenbach, T.M., Rescorla, L.A., 2004. The Achenbach System of Empirically Based Assessment (ASEBA) for Ages 1.5 to 18 Years, in: The Use of Psychological Testing for Treatment Planning and Outcomes Assessment: Instruments for Children and Adolescents, Volume 2, 3rd Ed. Lawrence Erlbaum Associates Publishers, Mahwah, NJ, US, pp. 179-213.

Akshoomoff, N., Beaumont, J.L., Bauer, P.J., Dikmen, S.S., Gershon, R.C., Mungas, D., Slotkin, J., Tulsky, D., Weintraub, S., Zelazo, P.D., 2013. VIII. NIH Toolbox Cognition Battery (CB): composite scores of crystallized, fluid, and overall cognition. Monogr. Soc. Res. Child Dev. 78, 119-132.

Alfano, C.A., Ginsburg, G.S., Kingery, J.N., 2007. Sleep-Related Problems Among Children and Adolescents With Anxiety Disorders. J. Am. Acad. Child Adolesc. Psychiatry 46, 224232. https://doi.org/10.1097/01.chi.0000242233.06011.8e

Baglioni, C., Nanovska, S., Regen, W., Spiegelhalder, K., Feige, B., Nissen, C., Reynolds, C.F., Riemann, D., 2016. Sleep and mental disorders: A meta-analysis of polysomnographic research. Psychol. Bull. 142, 969-990. https://doi.org/10.1037/bul0000053

Broyd, S.J., Demanuele, C., Debener, S., Helps, S.K., James, C.J., Sonuga-Barke, E.J.S., 2009. Default-mode brain dysfunction in mental disorders: a systematic review.

Neurosci. Biobehav. Rev. 33, 279-296. https://doi.org/10.1016/j.neubiorev.2008.09.002

Bruni, O., Ottaviano, S., Guidetti, V., Romoli, M., Innocenzi, M., Cortesi, F., Giannotti, F., 1996. The Sleep Disturbance Scale for Children (SDSC). Construction and validation of an instrument to evaluate sleep disturbances in childhood and adolescence. J. Sleep Res. 5, 251-261. https://doi.org/10.1111/j.1365-2869.1996.00251.x

Casey, B.J., Cannonier, T., Conley, M.I., Cohen, A.O., Barch, D.M., Heitzeg, M.M., Soules, M.E., Teslovich, T., Dellarco, D.V., Garavan, H., Orr, C.A., Wager, T.D., Banich, M.T., Speer, N.K., Sutherland, M.T., Riedel, M.C., Dick, A.S., Bjork, J.M., Thomas, K.M., Chaarani, B., Mejia, M.H., Hagler, D.J., Daniela Cornejo, M., Sicat, C.S., Harms, M.P., Dosenbach, N.U.F., Rosenberg, M., Earl, E., Bartsch, H., Watts, R., Polimeni, J.R., Kuperman, J.M., Fair, D.A., Dale, A.M., ABCD Imaging Acquisition Workgroup, 2018. The Adolescent Brain Cognitive Development (ABCD) study: Imaging acquisition across 21 sites. Dev. Cogn. Neurosci. 32, 43-54. https://doi.org/10.1016/j.dcn.2018.03.001

Caspi, A., Moffitt, T.E., 2018. All for One and One for All: Mental Disorders in One Dimension. Am. J. Psychiatry 175, 831-844. https://doi.org/10.1176/appi.ajp.2018.17121383

Chee, M.W.L., Zhou, J., 2019. Functional connectivity and the sleep-deprived brain, in: Progress in Brain Research. Elsevier, pp. 159-176. https://doi.org/10.1016/bs.pbr.2019.02.009

Cox, R.C., Olatunji, B.O., 2016. A systematic review of sleep disturbance in anxiety and related disorders. J. Anxiety Disord. 37, 104-129. https://doi.org/10.1016/j.janxdis.2015.12.001

De Havas, J.A., Parimal, S., Soon, C.S., Chee, M.W.L., 2012. Sleep deprivation reduces default mode network connectivity and anti-correlation during rest and task performance. Neurolmage 59, 1745-1751. https://doi.org/10.1016/j.neuroimage.2011.08.026

Dick, A.S., Lopez, D.A., Watts, A.L., Heeringa, S., Reuter, C., Bartsch, H., Fan, C.C., Kennedy, D.N., Palmer, C., Marshall, A., Haist, F., Hawes, S., Nichols, T.E., Barch, D.M., Jernigan, T.L., Garavan, H., Grant, S., Pariyadath, V., Hoffman, E., Neale, M., Stuart, E.A., Paulus, M.P., Sher, K.J., Thompson, W.K., 2021. Meaningful associations in the adolescent brain cognitive development study. Neurolmage 239, 118262. https://doi.org/10.1016/j.neuroimage.2021.118262

Emslie, G.J., Kennard, B.D., Mayes, T.L., Nakonezny, P.A., Zhu, L., Tao, R., Hughes, C., Croarkin, P., 2012. Insomnia moderates outcome of serotonin-selective reuptake inhibitor treatment in depressed youth. J. Child Adolesc. Psychopharmacol. 22, 21-28. https://doi.org/10.1089/cap.2011.0096 
medRxiv preprint doi: https://doi.org/10.1101/2021.08.12.21261990; this version posted August 13, 2021. The copyright holder for this preprint (which was not certified by peer review) is the author/funder, who has granted medRxiv a license to display the preprint in perpetuity. It is made available under a CC-BY-NC-ND 4.0 International license .

Fair, D.A., Cohen, A.L., Power, J.D., Dosenbach, N.U.F., Church, J.A., Miezin, F.M., Schlaggar, B.L., Petersen, S.E., 2009. Functional Brain Networks Develop from a "Local to Distributed" Organization. PLOS Comput. Biol. 5, e1000381. https://doi.org/10.1371/journal.pcbi.1000381

Finn, E.S., Shen, X., Scheinost, D., Rosenberg, M.D., Huang, J., Chun, M.M., Papademetris, X., Constable, R.T., 2015. Functional connectome fingerprinting: identifying individuals using patterns of brain connectivity. Nat. Neurosci. 18, 1664-1671. https://doi.org/10.1038/nn.4135

Fischl, B., Salat, D.H., Busa, E., Albert, M., Dieterich, M., Haselgrove, C., van der Kouwe, A., Killiany, R., Kennedy, D., Klaveness, S., Montillo, A., Makris, N., Rosen, B., Dale, A.M., 2002. Whole brain segmentation: automated labeling of neuroanatomical structures in the human brain. Neuron 33, 341-355. https://doi.org/10.1016/s0896-6273(02)00569-x

Fox, M.D., Snyder, A.Z., Vincent, J.L., Corbetta, M., Van Essen, D.C., Raichle, M.E., 2005. The human brain is intrinsically organized into dynamic, anticorrelated functional networks. Proc. Natl. Acad. Sci. 102, 9673-9678.

Gabrieli, J.D.E., Ghosh, S.S., Whitfield-Gabrieli, S., 2015. Prediction as a humanitarian and pragmatic contribution from human cognitive neuroscience. Neuron 85, 11-26. https://doi.org/10.1016/j.neuron.2014.10.047

Goldstone, A., Javitz, H.S., Claudatos, S.A., Buysse, D.J., Hasler, B.P., de Zambotti, M., Clark, D.B., Franzen, P.L., Prouty, D.E., Colrain, I.M., Baker, F.C., 2020. Sleep Disturbance Predicts Depression Symptoms in Early Adolescence: Initial Findings From the Adolescent Brain Cognitive Development Study. J. Adolesc. Health 66, 567-574. https://doi.org/10.1016/j.jadohealth.2019.12.005

Gordon, E.M., Laumann, T.O., Adeyemo, B., Huckins, J.F., Kelley, W.M., Petersen, S.E., 2016. Generation and Evaluation of a Cortical Area Parcellation from Resting-State Correlations. Cereb. Cortex 26, 288-303. https://doi.org/10.1093/cercor/bhu239

Gregory, A.M., Caspi, A., Eley, T.C., Moffitt, T.E., Oconnor, T.G., Poulton, R., 2005. Prospective longitudinal associations between persistent sleep problems in childhood and anxiety and depression disorders in adulthood. J. Abnorm. Child Psychol. 33, 157-163. https://doi.org/10.1007/s10802-005-1824-0

Gregory, A.M., Rijsdijk, F.V., Lau, J.Y.F., Dahl, R.E., Eley, T.C., 2009. The Direction of Longitudinal Associations Between Sleep Problems and Depression Symptoms: A Study of Twins Aged 8 and 10 Years. Sleep 32, 189-199.

Gregory, A.M., Sadeh, A., 2016. Annual Research Review: Sleep problems in childhood psychiatric disorders--a review of the latest science. J. Child Psychol. Psychiatry 57, 296-317. https://doi.org/10.1111/jcpp.12469

Gu, S., Satterthwaite, T.D., Medaglia, J.D., Yang, M., Gur, R.E., Gur, R.C., Bassett, D.S., 2015. Emergence of system roles in normative neurodevelopment. Proc. Natl. Acad. Sci. 112, 13681-13686. https://doi.org/10.1073/pnas.1502829112

Hagler, D.J., Hatton, SeanN., Cornejo, M.D., Makowski, C., Fair, D.A., Dick, A.S., Sutherland, M.T., Casey, B.J., Barch, D.M., Harms, M.P., Watts, R., Bjork, J.M., Garavan, H.P., Hilmer, L., Pung, C.J., Sicat, C.S., Kuperman, J., Bartsch, H., Xue, F., Heitzeg, M.M., Laird, A.R., Trinh, T.T., Gonzalez, R., Tapert, S.F., Riedel, M.C., Squeglia, L.M., Hyde, L.W., Rosenberg, M.D., Earl, E.A., Howlett, K.D., Baker, F.C., Soules, M., Diaz, J., de Leon, O.R., Thompson, W.K., Neale, M.C., Herting, M., Sowell, E.R., Alvarez, R.P., Hawes, S.W., Sanchez, M., Bodurka, J., Breslin, F.J., Morris, A.S., Paulus, M.P., Simmons, W.K., Polimeni, J.R., van der Kouwe, A., Nencka, A.S., Gray, K.M., Pierpaoli, C., Matochik, J.A., Noronha, A., Aklin, W.M., Conway, K., Glantz, M., Hoffman, E., Little, R., Lopez, M., Pariyadath, V., Weiss, S.RB., Wolff-Hughes, D.L., DelCarmen-Wiggins, R., Feldstein Ewing, S.W., Miranda-Dominguez, O., Nagel, B.J., Perrone, A.J., Sturgeon, D.T., Goldstone, A., Pfefferbaum, A., Pohl, K.M., Prouty, D., Uban, K., Bookheimer, S.Y., 
Dapretto, M., Galvan, A., Bagot, K., Giedd, J., Infante, M.A., Jacobus, J., Patrick, K., Shilling, P.D., Desikan, R., Li, Y., Sugrue, L., Banich, M.T., Friedman, N., Hewitt, J.K., Hopfer, C., Sakai, J., Tanabe, J., Cottler, L.B., Nixon, S.J., Chang, L., Cloak, C., Ernst, T., Reeves, G., Kennedy, D.N., Heeringa, S., Peltier, S., Schulenberg, J., Sripada, C., Zucker, R.A., lacono, W.G., Luciana, M., Calabro, F.J., Clark, D.B., Lewis, D.A., Luna, B., Schirda, C., Brima, T., Foxe, J.J., Freedman, E.G., Mruzek, D.W., Mason, M.J., Huber, R., McGlade, E., Prescot, A., Renshaw, P.F., Yurgelun-Todd, D.A., Allgaier, N.A., Dumas, J.A., Ivanova, M., Potter, A., Florsheim, P., Larson, C., Lisdahl, K., Charness, M.E., Fuemmeler, B., Hettema, J.M., Maes, H.H., Steinberg, J., Anokhin, A.P., Glaser, P., Heath, A.C., Madden, P.A., Baskin-Sommers, A., Constable, R.T., Grant, S.J., Dowling, G.J., Brown, S.A., Jernigan, T.L., Dale, A.M., 2019. Image processing and analysis methods for the Adolescent Brain Cognitive Development Study. Neurolmage 202, 116091. https://doi.org/10.1016/j.neuroimage.2019.116091

Hansen, B.H., Skirbekk, B., Oerbeck, B., Wentzel-Larsen, T., Kristensen, H., 2014. Associations between sleep problems and attentional and behavioral functioning in children with anxiety disorders and ADHD. Behav. Sleep. Med. 12, 53-68. https://doi.org/10.1080/15402002.2013.764525

Jansen, P.W., Saridjan, N.S., Hofman, A., Jaddoe, V.W.V., Verhulst, F.C., Tiemeier, H., 2011. Does disturbed sleeping precede symptoms of anxiety or depression in toddlers? The generation R study. Psychosom. Med. 73, 242-249. https://doi.org/10.1097/PSY.0b013e31820a4abb

Johnson, W.E., Li, C., Rabinovic, A., 2007. Adjusting batch effects in microarray expression data using empirical Bayes methods. Biostatistics 8, 118-127. https://doi.org/10.1093/biostatistics/kxj037

Kaufmann, T., Elvsåshagen, T., Alnæs, D., Zak, N., Pedersen, P.Ø., Norbom, L.B., Quraishi, S.H., Tagliazucchi, E., Laufs, H., Bjørnerud, A., Malt, U.F., Andreassen, O.A., Roussos, E., Duff, E.P., Smith, S.M., Groote, I.R., Westlye, L.T., 2016. The brain functional connectome is robustly altered by lack of sleep. Neurolmage 127, 324-332. https://doi.org/10.1016/j.neuroimage.2015.12.028

Kessler, R.C., Amminger, G.P., Aguilar-Gaxiola, S., Alonso, J., Lee, S., Ustün, T.B., 2007. Age of onset of mental disorders: a review of recent literature. Curr. Opin. Psychiatry 20, 359-364. https://doi.org/10.1097/YCO.0b013e32816ebc8c

Lees, B., Squeglia, L.M., McTeague, L.M., Forbes, M.K., Krueger, R.F., Sunderland, M., Baillie, A.J., Koch, F., Teesson, M., Mewton, L., 2021. Altered Neurocognitive Functional Connectivity and Activation Patterns Underlie Psychopathology in Preadolescence. Biol. Psychiatry Cogn. Neurosci. Neuroimaging 6, 387-398. https://doi.org/10.1016/j.bpsc.2020.09.007

Linhartová, P., Látalová, A., Kóša, B., Kašpárek, T., Schmahl, C., Paret, C., 2019. fMRI neurofeedback in emotion regulation: A literature review. Neurolmage 193, 75-92. https://doi.org/10.1016/j.neuroimage.2019.03.011

Liu, X., Buysse, D.J., Gentzler, A.L., Kiss, E., Mayer, L., Kapornai, K., Vetró, A., Kovacs, M., 2007. Insomnia and hypersomnia associated with depressive phenomenology and comorbidity in childhood depression. Sleep 30, 83-90.

McTeague, L.M., Huemer, J., Carreon, D.M., Jiang, Y., Eickhoff, S.B., Etkin, A., 2017. Identification of Common Neural Circuit Disruptions in Cognitive Control Across Psychiatric Disorders. Am. J. Psychiatry 174, 676-685. https://doi.org/10.1176/appi.ajp.2017.16040400

Menon, V., 2011. Large-scale brain networks and psychopathology: a unifying triple network model. Trends Cogn. Sci. 15, 483-506. https://doi.org/10.1016/j.tics.2011.08.003

Miller, K., Alfaro-Almagro, F., Bangerter, N., Thomas, D.L., Yacoub, E., Xu, J., Bartsch, A., Jbabdi, S., Sotiropoulos, S., Andersson, J., Griffanti, L., Douaud, G., Okell, T., Weale, 
medRxiv preprint doi: https://doi.org/10.1101/2021.08.12.21261990; this version posted August 13, 2021. The copyright holder for this preprint (which was not certified by peer review) is the author/funder, who has granted medRxiv a license to display the preprint in perpetuity. It is made available under a CC-BY-NC-ND 4.0 International license .

P., Dragonu, I., Garratt, S., Hudson, S., Collins, R., Jenkinson, M., Matthews, P., Smith, S.M., 2016. Multimodal population brain imaging in the UK Biobank prospective epidemiological study. Nat. Neurosci. https://doi.org/10.1038/nn.4393

Noble, S., Scheinost, D., Constable, R.T., 2019. A decade of test-retest reliability of functional connectivity: A systematic review and meta-analysis. Neurolmage 203, 116157. https://doi.org/10.1016/j.neuroimage.2019.116157

Ohi, K., Ochi, R., Noda, Y., Wada, M., Sugiyama, S., Nishi, A., Shioiri, T., Mimura, M., Nakajima, S., 2021. Polygenic risk scores for major psychiatric and neurodevelopmental disorders contribute to sleep disturbance in childhood: Adolescent Brain Cognitive Development (ABCD) Study. Transl. Psychiatry 11, 1-11. https://doi.org/10.1038/s41398-021-01308-8

Sämann, P.G., Tully, C., Spoormaker, V.I., Wetter, T.C., Holsboer, F., Wehrle, R., Czisch, M., 2010. Increased sleep pressure reduces resting state functional connectivity. Magn. Reson. Mater. Phys. Biol. Med. 23, 375-389. https://doi.org/10.1007/s10334-010-0213-z

Scott, N., Blair, P.S., Emond, A.M., Fleming, P.J., Humphreys, J.S., Henderson, J., Gringras, P., 2013. Sleep patterns in children with ADHD: a population-based cohort study from birth to 11 years. J. Sleep Res. 22, 121-128. https://doi.org/10.1111/j.13652869.2012.01054.x

Sha, Z., Wager, T.D., Mechelli, A., He, Y., 2019. Common Dysfunction of Large-Scale Neurocognitive Networks Across Psychiatric Disorders. Biol. Psychiatry 85, 379-388. https://doi.org/10.1016/j.biopsych.2018.11.011

Tesler, N., Gerstenberg, M., Huber, R., 2013. Developmental changes in sleep and their relationships to psychiatric illnesses. Curr. Opin. Psychiatry 26, 572-579. https://doi.org/10.1097/YCO.0b013e328365a335

Wager, T.D., Davidson, M.L., Hughes, B.L., Lindquist, M.A., Ochsner, K.N., 2008. Prefrontalsubcortical pathways mediating successful emotion regulation. Neuron 59, 1037-1050.

Wager, T.D., Waugh, C.E., Lindquist, M., Noll, D.C., Fredrickson, B.L., Taylor, S.F., 2009. Brain mediators of cardiovascular responses to social threat: part I: Reciprocal dorsal and ventral sub-regions of the medial prefrontal cortex and heart-rate reactivity. Neurolmage 47, 821-835. https://doi.org/10.1016/j.neuroimage.2009.05.043

Woo, C.-W., Chang, L.J., Lindquist, M.A., Wager, T.D., 2017. Building better biomarkers: brain models in translational neuroimaging. Nat. Neurosci. 20, 365-377. https://doi.org/10.1038/nn.4478

Yang, F.N., Bronshteyn, M., Flowers, S.A., Dawson, M., Kumar, P., Rebeck, G.W., Turner, R.S., Moore, D.J., Ellis, R.J., Jiang, X., 2021. Low CD4 nadir exacerbates the impacts of APOE $\varepsilon 4$ on functional connectivity and memory in adults with HIV. AIDS Publish Ahead of Print. https://doi.org/10.1097/QAD.0000000000002840

Yu, M., Linn, K.A., Cook, P.A., Phillips, M.L., Mclnnis, M., Fava, M., Trivedi, M.H., Weissman, M.M., Shinohara, R.T., Sheline, Y.I., 2018. Statistical harmonization corrects site effects in functional connectivity measurements from multi-site fMRI data. Hum. Brain Mapp. 39, 4213-4227. https://doi.org/10.1002/hbm.24241 